\title{
Payments In-Lieu-Of Taxes Between Federal And Local Governments And The Siting Of Federally-Owned Waste Isolation Activities \#
}

\author{
David J. Bjornstad* \\ and \\ Kim-Elaine Johnson**
}

\section{INTRODUCTION}

This analysis considers the costs that accrue to a local economy when a high level nuclear waste isolation facility is sited, and it seeks to evaluate ways to deal with these costs through the local public sector. Like most hazardous material handling facilities, the nuclear waste isolation center is viewed by communities as an unattractive addition. To accept such a center willingly, a community must perceive that it is compensated in some way for the extraordinary costs it must bear or that it bears an equitable share of a larger set of costs. ${ }^{1}$ One way to compensate communities and to assign the costs to the facilities' beneficiaries is to assess local taxes. However, in a strict sense, this option is not open since the federal government, which will own the waste isolation facility, is exempt from state and local taxation. Instead, a system of payments-in-lieu-of-taxes (PILOT) or other fiscal relationships may be necessary if compensation is to be paid.

In general, two types of costs accrue to communities from siting a nuclear waste isolation facility. These give rise to the need for two types of compensating payments. The first, payments-in-lieu-of-taxes or PILOT, results from the tax exempt nature of the federal facility and are justified on the grounds that the federal government has a responsibility to pay its own way when it acts as a public marketeer. ${ }^{2}$ Interpretations of the fiscal liability incurred range from paying the marginal costs of facility public service requirements to paying the opportunity costs including foregone

\#This research was sponsored by the Office of Nuclear Waste Isolation, U. S. Department of Energy under contract W-7405-eng-26 with the Union Carbide Corporation. The authors wish to express their appreciation to William Fox of the University of Tennessee, Knoxville, and to Robert Shelton, David Vogt, and Ruth Maddigan of Economic Systems Analysis, Incorporated for helpful comments on earlier drafts of this paper.

*Economic Analysis Section, Energy Division, Oak Ridge National Laboratory, Oak Ridge, Tennessee 37830.

**Texas Public Utility Commission. 
tax revenues. This latter argument is particularly germane since in the case of the nuclear waste facility, the dedication of the site to tax-exempt use may be permanent and is certainly long term. Most studies of federal liability under related circumstances have attempted to apply this cost principle in one form or another (see, for example, Williams, 1955; Balk, 1971; and Quigley and Schmenner, 1975). The federal government, however, has usually been unwilling to accept a "tax-like" obligation, particularly one that municipalities could modify by manipulation of their tax rates (Raimondo, 1980).

The second type of payment is justified on the grounds that the facility also imposes costs on other, nonhost communities. These costs may be described as external (externalities), since they accrue to communities apart from the facility. Nevertheless, they are quite important for waste facilities since communities may view perceived or potential costs as more damaging than such measurable social "bads" as air or noise pollution. Some might even argue that the existence of these extraordinary costs (referred to hereafter as risks) alone justify placing facilities of this type in the public sector. To the extent this is true, the development of specialized federal/local relationships may be necessary. ${ }^{3}$

This paper presents an analysis of transfer payment mechanisms that could address these cost issues. A simple model of the local economy is developed and used to analyze the choices which a community must make in the provision of public and private goods, and this model is applied to the PILOT question. Next, a discussion of externalities and tax/subsidy schemes is presented and the options analyzed through the local economic model. In the final section, a summary is given.

\section{A SIMPLE MODEL OF PUBLIC/PRIVATE GOODS}

Assume a local economy that makes choices between the consumption of two commodities: private goods and local public goods. Private goods are measured as disposable (after tax) income streams emanating from local house-hold and business sectors. Local public goods are also measured in dollar terms as local public expenditures and are purchased by giving up private goods. We assume that local public goods do not exhibit the same joint supply characteristics as pure public goods, and increasing the number of local residents requires proportionate increases of local public goods to maintain per capita levels of satisfaction. The primary distinction between private goods and local public goods is that while private goods are financed through a price system, local public goods are financed through a tax on income which is applied equally on each household and business unit. In evaluating the trade off between public and private goods, local decision units evaluate private goods foregone through this tax program. ${ }^{4}$ It is convenient to think of local public goods as either a single commodity or as a composite bundle of individual commodities consumed in fixed proportions, to avoid scaling problems in measurement. Given this interpretation and given fixed factor proportions and 
prices in the production of the public good, the dollar value of the local public good can be equated to the revenue yield of the local tax system, assuming no intergovernmental revenue transfers are paid or received and that the local public budget is in balance.

.If we assume the existence of a community preference function, we can determine equilibrium levels of public and private goods. Given a family of ordinal preference functions $\mathrm{I}_{\mathrm{i}}$, the community consumes $\mathrm{OX}_{1}$ unit of public goods and $\mathrm{OY}_{1}$ units of private goods (Fig. 1). To obtain this level of public goods $\mathrm{Y}_{0} \mathrm{Y}_{1}$ private goods must be given up. Thus, given preferences and income, the choice of a level of disposable income and public expenditures defines a tax rate, which is shown in Fig. 2 as $\mathrm{Y}_{0} \mathrm{Y}_{1} / \mathrm{OY}_{0}$. Local taxable capacity is defined as $\mathrm{OX}_{0}$. When local income and local taxable capacity grow proportionately, the "price" of public goods, i.e., the rate at which local public and private goods can be substituted, remain constant. Moreover, given a series of shifts in $\mathrm{Y}_{0} \mathrm{X}_{0}$ the resulting locus of equilibrium points will describe a ray from the origin, implying a unitary income elasticity of demand for public goods at all incomes. ${ }^{5}$

It is possible, of course, that proportionate growth will not occur and that private sector income will not be translated into taxable capacity on a one-to-one basis. One goal of communities is to increase taxable capacity

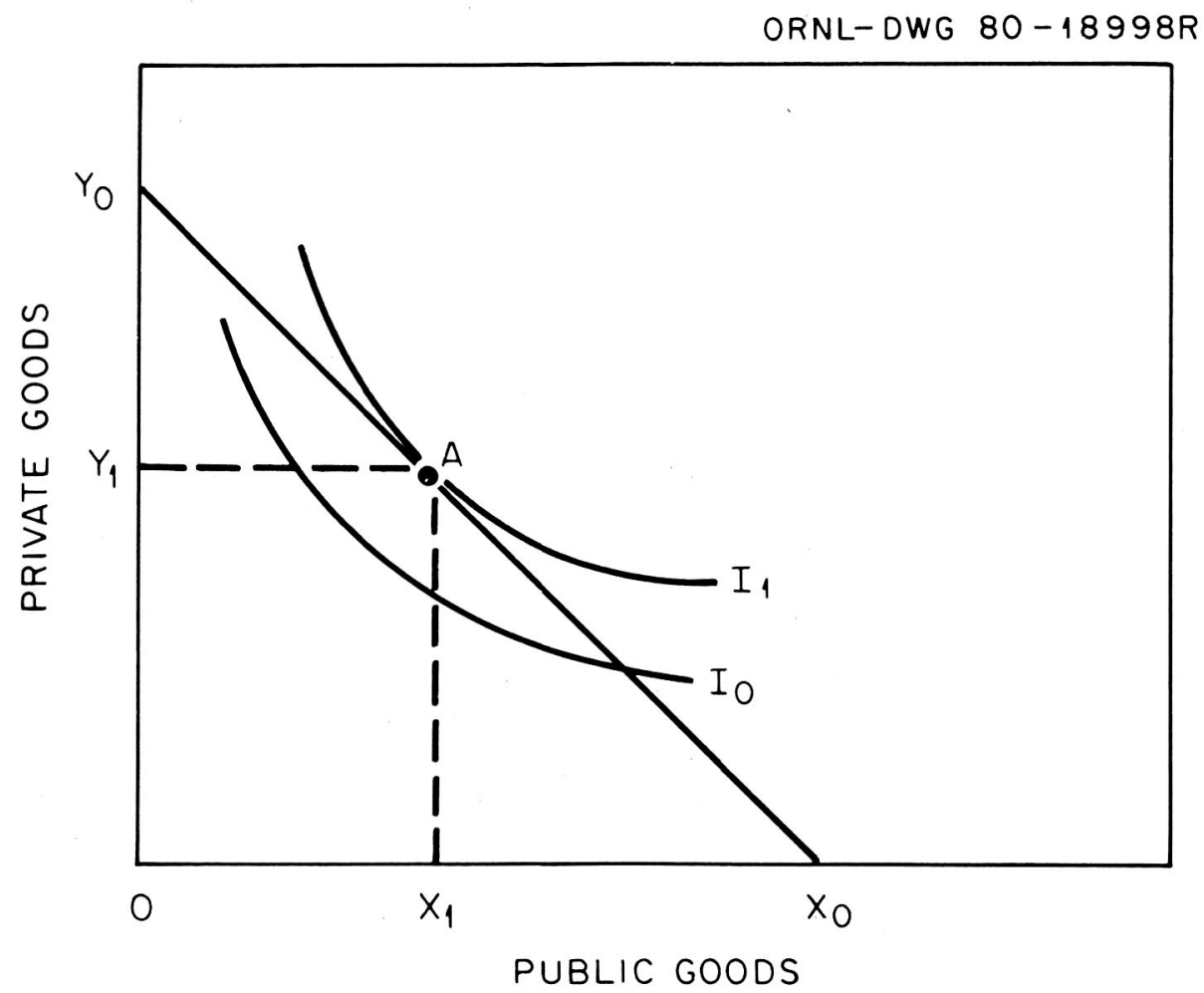

Fig. 1. Equilibrium Levels of Public and Private Goods 


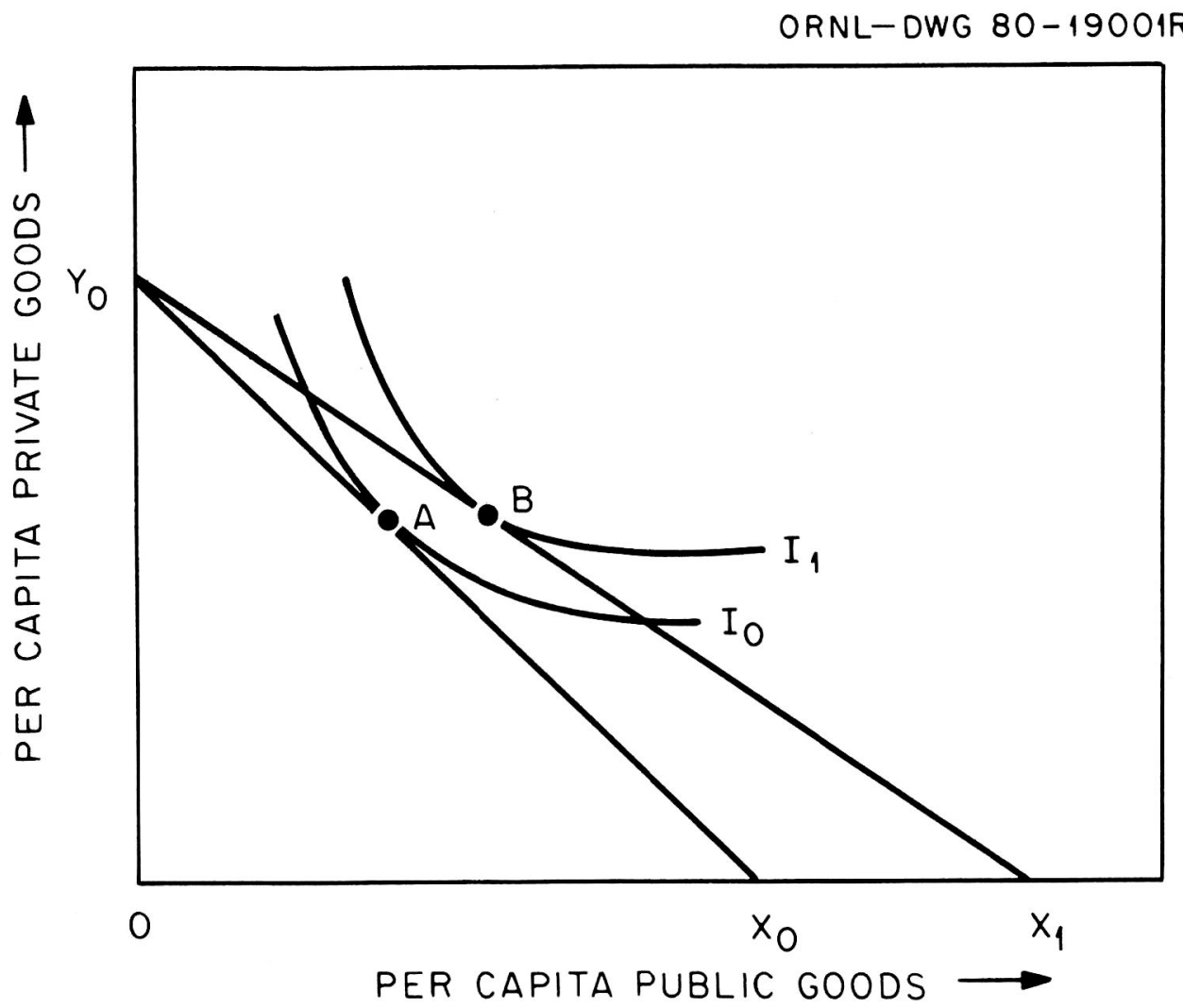

Fig. 2. A Change in Taxable Capacity

relative to income by such devices as the exportation of taxes. ${ }^{6}$ From the view of the local voter, this lowers the effective price of public goods, since local tax dollars are supplemented by imported ones. When taxable capacity grows less rapidly than private income, public goods become more expensive relative to private goods. This occurs, for example, when industries are given "tax breaks" or when exempt property is placed on the tax roll.

Because no permanent high level radioactive waste facilities have yet been constructed, there are no actual data with which to measure the impact on communities of siting these facilities. There is, however, sufficient information available concerning the facilities themselves to anticipate some impacts. It is expected that high capital-labor ratios will prevail. Security may well dictate that plant public services be internally provided, and the relatively low level of labor required will minimize the public service impact on the community. On the other hand, the communities where waste sites are likely to be located will be in extremely rural areas. Thus, the small absolute change in population could well mean a large percentage change for the community. This condition would necessitate 
large increases in such public services as schools, sewer capacity, water, roads, and electric lines. Of additional and perhaps highest importance, these facilities are likely to be constructed and operated by the federal government which is exempt from payment of state and local taxes. Successful deployment of this technology may, therefore, depend upon the creation of incentives for communities to host high level waste facilities, and incentives, in turn, are based on compensation of all costs, at minimum. As noted above, it simplifies matters to take up the issue of compensation/incentives in two stages: (1) the loss of potential tax revenue for host communities; and (2) external costs for other communities. We shall now address these isssues sequentially.

\section{INGENTIVES AND DISINCENTIVES DUE TO PAYMENTS-IN- LIEU-OF TAXES}

A number of changes will accompany the siting of a high level waste facility that are relevant to this analysis. First, the level of private sector activity will increase due to the influx of workers to operate the facility. We omit consideration of the impacts from the construction stage in order to focus on long-term institutional arrangements, with the caveat that significant and unique costs can accompany construction. Assuming the community was in the position shown in Fig. 1 initially, the addition of private sector activity could cause the average income of the local voter to either increase or decrease. The second change concerns the new level of taxable capacity relative to private income evaluated by the local voter. The precise change would depend on a number of factors. Under balanced growth, proportionate changes in private goods and taxable capacity would occur. Balanced growth, however, would be unlikely. Were the isolation facility privately owned and subject to taxation, one would expect taxable capacity to increase more rapidly than private sector activity. ${ }^{7}$ Because the facility is federally owned and not subject to taxation, taxable capacity can increase only due to growth in the household sector. Prior to the siting, local voters evaluated a budget constraint which reflected the average taxable status of other citizens, including the activities in which they work. To the extent that newcomers have similar incomes to old residents, $\mathrm{OY}_{0}$ will not change. However, since there is no taxable business activity associated with newcomers working in a federally-owned facility, taxable capacity will increase only due to new household income. No increase will occur due to business sector income, and the "price" of public goods relative to private goods may increase as per capita taxable capacity decreases.

To put this into more concrete terms, it is useful to distinguish three cases which are relevant to the waste isolation facility: (1) private sector ownership, (2) public ownership without PILOT, and (3) public ownership with PILOT.

Focusing on the first case, the impact of the facility on the local public sector will depend largely on the taxable characteristics of the facility ${ }^{8}$ If workers receive salaries equivalent to those of their counterparts in other 
local industries, $\mathrm{OY}_{0}$ will not change. To the extent the facility income is large relative to worker income, i.e., that the facility is capital intensive, per capita taxable capacity will rise and the price of public goods, relative to private goods, will decrease. Figure 2 illustrates this circumstance. Although the final mix of goods will depend upon the "price" elasticity of demand for local public goods of the local voter, all points on $Y_{0} X_{1}$ lie above those on $\mathrm{Y}_{0} \mathrm{X}_{0}$, and the change is Pareto superior. The community could leave its tax rate unchanged and enjoy per capita increases in public goods with no loss in private goods or could hold constant the level of public goods and enjoy a higher per capita level of private goods by lowering the tax rate.

The second case occurs under federal ownership when there are no PILOT or other transfers between the facility and the community. In this case also, the per capita level of private goods remains constant, but since newcomers arrive, the per capita level of taxable capacity falls (i.e., in Fig. 2 one moves from $\mathrm{X}_{1}$ to $\mathrm{X}_{0}$ ). This assumes that households brought in by siting the facility do not pay their own way through taxable capacity increases associated with the household alone, since on an average, house-

ORNL-DWG $80-19003 R 2$

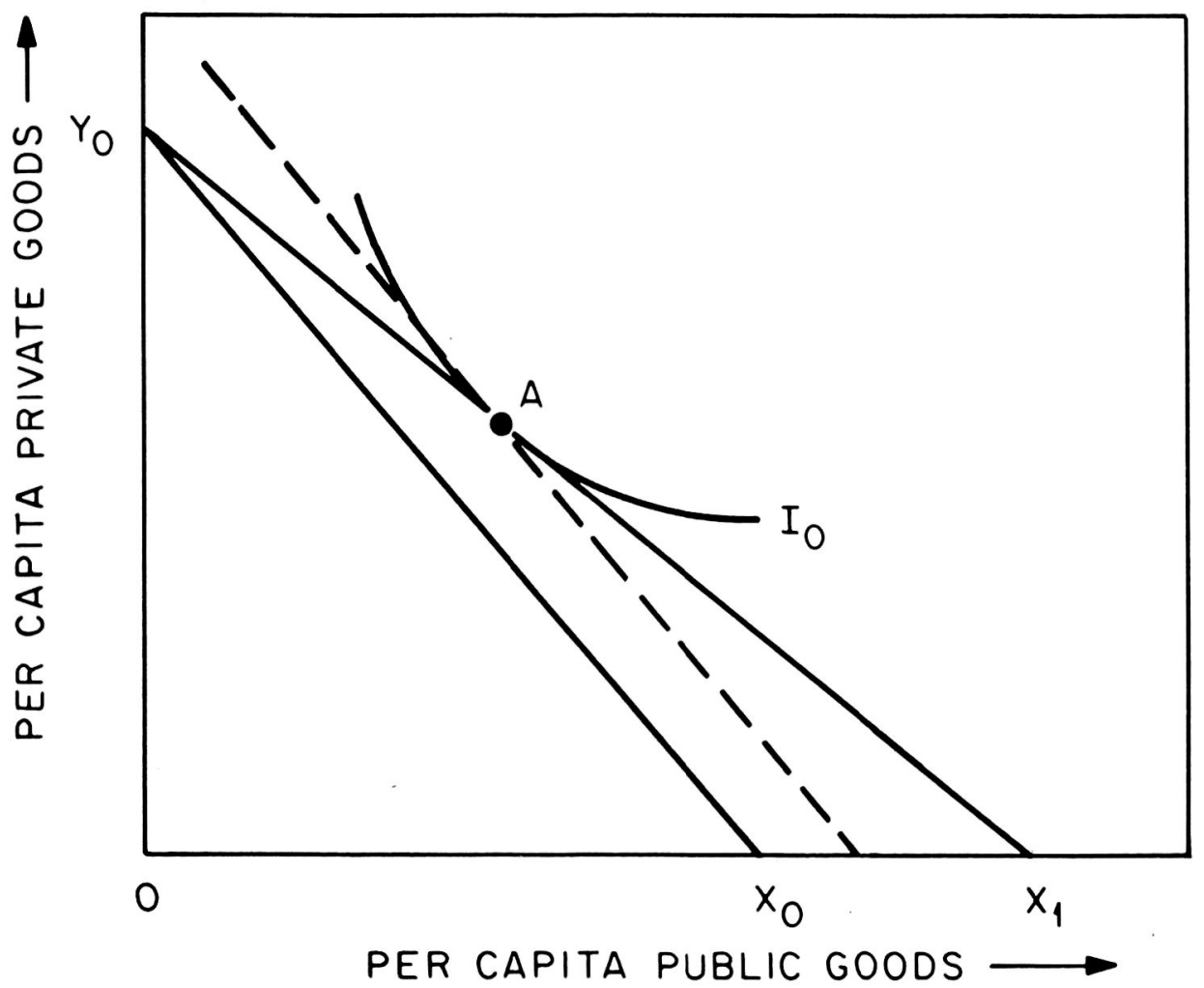

Fig. 3. A Lump-Sum Payment Allowing Purchase of Bundle "A" 


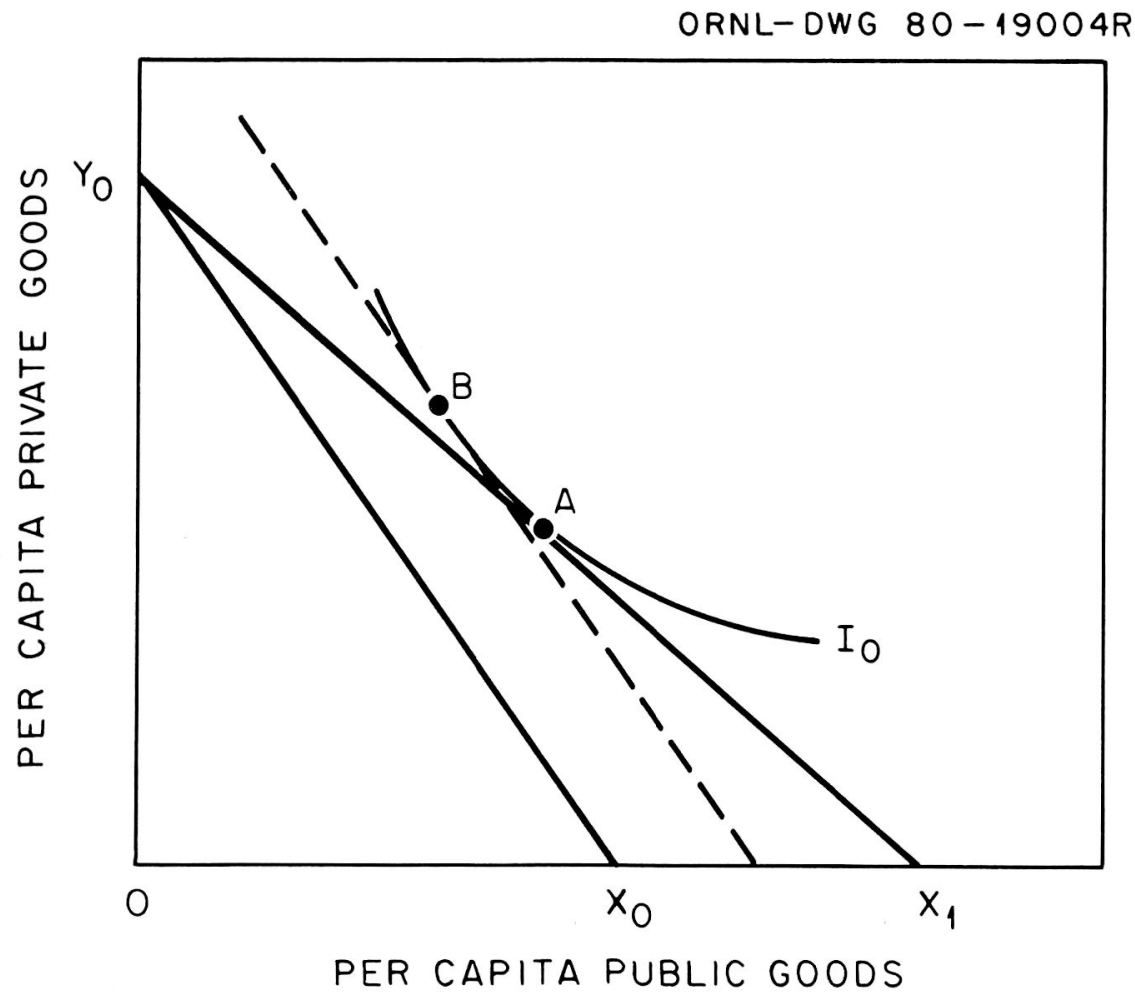

Fig. 4. A Lump-Sum Payment Allowing Constant Utility

holds in the community are associated with taxable facilities (i.e., they work in facilities that are subject to taxation). Again, the price elasticity of the local voter's demand for public services will determine the exact outcome, but to obtain the same per capita level of services as prior to the siting would require increasing the tax rate and consuming smaller quantities of private goods. Conversely, to consume the same per capita level of private income, a lower level of public services must be accepted. In either case, all points on $\mathrm{Y}_{0} \mathrm{X}_{0}$ fall below those in $\mathrm{Y}_{0} \mathrm{X}_{1}$, and a loss in utility occurs.

With regard to the third case, a variety of PILOT schemes exist. On the one hand, the Federal Government may opt to make payments exactly as if it were subject to taxation. The payment made to the community would change as the tax rate changes, and the ultimate tax payment would depend upon the price elasticity of the local voter. In this case, the same conclusions drawn with respect to the taxable case would obtain. This is termed the tax equivalence method. A second option would be for the Federal Government to make a lump sum payment equal to that which would occur if the plants were taxable. This solution would be patterned after option one, but payments would not change as tax rates change; hence, the community would face a different price ratio than under the tax equivalence scheme. This result is shown in Fig. 3. 
Note that in this case the government has two options. The first is to make payments which would permit choosing the per capita public-private good bundle originally chosen in Fig. 3. Under the new price ratio, bundle A would no longer be chosen. The exact bundle to be chosen is indeterminate, but as long as preferences do not change and private goods are normal, the solution will be above and to the left of A. ${ }^{9}$ The second option is to make lump-sum payments which would permit obtaining the same level of utility as that under the tax equivalence scheme. Under this option, the original commodity bundle A would again not be chosen, but for normal preferences, some B which lies to the northwest of A would always be chosen, as can be seen in Fig. 4.

A range of other options is available to the Federal Government, most of which are predicated on some system of compensating the community for the facility, while preventing the "windfall" gains possible if a tax equivalence model were adopted. Most "cost compensation" approaches can be shown to be specious since they reflect only out-of-pocket costs and neglect the fact that the site might have been used for some other taxable purpose. For example, the payment may be based on a limited concept of opportunity cost whereby the chosen payment size is equal to the payment which the lands, occupied by the facility, made prior to acquisition. Such payments implicitly assume that save for the facility, the site would have remained forever vacant.

Another cost compensation device would make payments equal to public service costs due to the facility. This plan overlooks the fact that most local public good expenditures are made on behalf of households rather than industries. If the marginal costs associated with the facility fail to include these, the average tax burden must increase if newcomers are added to the community and the service level is to be maintained. It is also possible that the facility will not represent the highest and best use of the industrial land in a local fiscal sense. In this case, the tax equivalency method may not truly represent opportunity costs. On the other hand, if windfall gains are an issue, the Federal Government can make compensatory payments to close the gap $\mathrm{X}_{0} \mathrm{X}_{1}$ in Fig. 3 while leaving $\mathrm{Y}_{0}$ intact. If such payments are chosen to obtain the original per capita feasible set given by $\mathrm{X}_{0} \mathrm{Y}_{0}$, the community would be exactly compensated by the facility. We term this the per capita equity method. If lump sum payments are made, the Federal Government would have to decide whether to apply the equal utility or equal revenue concept, as previously discussed.

We can now summarize these results in terms of incentives for communities to host federal facilities. If the Federal Government wishes to compensate local governments on par with the private sector, insofar as local taxes are concerned, it will adopt the tax equivalence scheme suggested by the ACIR (1980). While there exist a number of theoretical nuances separating the tax-rate-based tax equivalence PILOT from the lump sum PILOT, each provides the community a positive incentive in the sense that it obtains a position Pareto superior to that prior to the siting. Of the cost compensation schemes, only the per capita equity method pro- 
vides a neutral incentive. The variety of schemes which measure site revenues prior to acquisition, or which measure facility marginal public service costs, will always leave the community on a lower indifference surface than prior to the siting. Siting will succeed in these instances only when the community perceives the benefits of the siting inaccurately or evaluates noneconomic benefits to be greater than economic and noneconomic costs.

\section{CREATING INCENTIVES TO OVERCOME RISKS}

The first portion of this analysis has assumed that waste isolation facilities are identical to privately owned facilities, except for their exemption from state and local taxes. However, the public generally perceives that facilities handling hazardous materials, particularly nuclear materials, generate extraordinary costs that exceed those of normal industrial enterprise. Since these costs fall on communities outside the host jurisdiction (as well as on the host jurisdiction) they can be treated as external costs. Because the Federal Government can cut across state and local boundaries in dealing with these costs, and because it can be held more completely responsible than the private sector for these and other potential costs, it is the logical body to operate this type of facility.

The existence of externalities is sufficient to justify payments to compensate for external costs due to risks. It is also possible that communities outside the host jurisdiction may influence the siting decision and in this way force the facility to recognize their costs. In either case, there is motivation for the facility to internalize these costs through transfer payments to impacted communities apart from the host jurisdiction. This section analyzes the characteristics of such payments.

To begin with, we must clarify the nature of external costs and benefits. Formally, externalities are said to arise when a transaction or activity by one or more parties causes benefits or costs to accrue to some third party not involved in the original transaction. If one hou sehold sprays mosquitos which bite members of other households in the neighborhood, the affected neighbors receive a benefit for which no charge is levied. Contrariwise, if the spraying household lays down such a noxious fog of chemicals that the neighbors' vegetation is killed or stunted, an external cost would be generated. In each case, the fact that third party preferences are not taken into account leads to the production of levels of goods that are not socially optimal. In the case of an external benefit, it can be shown that social benefit (and therefore demand) exceeds private benefit and that underproduction will occur. For the external cost case, the entity producing the good does not bear the full costs of its actions, and over-production occurs.

A rather extensive literature describes remedies to the externality problem. Ronald Coase (1960) has shown that where affected parties bargain, the external cost or benefit may be internalized and optimality achieved. Some, however, fault the Coasian solution because of free rider problems 
and capital market imperfection (see Baumol, 1972; Baumol and Oates, 1975; Kneese and Bower, 1968; Pigou, 1924). Critics often argue for a system of per unit taxes on pollutant outputs and corresponding payments to those suffering from pollutant costs. Although there is no final resolution to this debate, we will focus on the tax and transfer mechanism because of its appeal to equity and its positive impact on reducing opposition to siting the facility.

One consideration in designing the compensation mechanism centers on the conditions under which the externality is produced. If one thinks of risks as a joint product which arises as waste isolation services are produced, one must ask if risks are produced in fixed or variable proportions. If risks can be reduced through the addition of capital or other factor inputs, the need to compensate will be reduced. For example, it is possible to add scrubbers to a coal-fired electric station to reduce pollution output while leaving electrical generation the same. The more that risks can be reduced in this manner, the less will be the need for reliance on fiscal transfers, although the costs of achieving risk reduction would still be borne by the facility. On the other hand, if risks and waste isolation services are produced in fixed proportions, the opportunity to reduce risks by increasing the costs of production is not available, and the burden of compensating for risks must be borne solely by the revenue transfer program.

A second consideration in this process is the nature of the utility function of the local voter in the communities bearing the external costs. Thus far, it has been implicitly assumed that this citizen is able to place a dollar value on the costs incurred from the waste isolation activity and is willing to accept a payment through the local public sector in exchange for bearing this cost. We shall continue this assumption below. However, it should be borne in mind that it is this subjective evaluation which determines how risks can be reduced since perceived risks are as important as actual risks. For example, if neighboring communities feel that risks are reduced by improving the vehicles on which radioactive wastes are transported, this becomes a risk reducing option. It may well be that these communities would prefer some combination of transfer payments and production outlays. It is also possible that no action on the part of the facility could either compensate or reduce these costs.

Finally, there remains the difficult problem of measuring the preferences of impacted communities regarding these external costs. First, there is no market information available upon which to base cost estimates directly. In the absence of this direct information, it will be necessary to either infer preferences indirectly or to create a pseudo-market (an auction perhaps) on which to base cost estimates. Second, if individuals are questioned as to preferences or if auction methods are used, there exists a strong incentive to overstate harms suffered. To the extent that a large number of sites are considered, it may be possible to approach an efficient solution. In this case, communities which overstate the harms they suffer are not likely to be selected as sites. Of course, without an incentive bonus of some sort, they would have no reason to respond in any manner. 
With these considerations in mind, the simple model developed above can now be applied to the externality question. In doing this, we may adopt one of two conventions in interpreting costs. We may view the costs as a modification to the community's preference function, where all previous levels of indifference are valued at a lower level following the imposition of the external cost, or we may view it as a reduction in real income whereby the budget constraint shifts to the left in a parallel fashion. Either method yields identical results, namely that identical proportions of private and public goods are consumed, and a lower level of utility is obtained. Thus, in principle, a system of "block grants" which bring about parallel outward shifts in the community's income constraint would be appropriate. Granted sufficient information on community preferences, one could choose the level of payments to either compensate communities equal to the loss incurred or provide incentives to accept the facility by permitting communities to achieve higher levels of utility than before the siting.

\section{CONCLUSIONS}

This paper has presented an analysis of transfer payments between a federally owned waste isolation facility and local governments affected by the facility. Two types of payments, in-lieu-of-taxes to the host community and block grants to other affected communities, are examined, and it is concluded that a variety of payment strategies are available. Some could provide incentives for communities which encourage siting.

An important aspect of this analysis has been to draw a distinction between the "compensation of costs" and the "provision of incentives." Unless a community can be shown to reach a higher level of indifference (utility) it will have no incentive to encourage the siting of a facility, whether or not the direct costs associated with the facility are compensated. Nevertheless, designing an intergovernmental revenue system that does provide incentives should not prove a difficult task.

This analysis also rests on a number of assumptions and utilizes a number of behavioral suppositions. First, it is assumed that a payments-inlieu-of-taxes scheme based on tax equivalency is indeed a feasible alternative. Currently, there are no major transfer payment programs that use this criterion. Second, it is assumed that waste facilities inherently contain elements of risk that must be compensated. If levels of risk can be minimized through siting schemes or design, the role played by transfer payments is reduced, and the design of the payments system is simplified. Third, it is assumed that communities are willing to trade off risk associated with waste facilities for transfer payments. Clearly, if this assumption is erroneous, or subject to special preconditions or qualifications, the probability of creating incentives is greatly altered.

Two sets of behavioral parameters are also highly important in successfully designing an incentive system based on transfer payments. The first regards the community response to the "price change" which occurs when a large increase in taxable capacity per worker is added to the tax roll. 
Estimating this parameter will require careful examination of the range of local governments in which the facility might be sited and will yield a range of payment estimates. The second important parameter is that which governs the rate at which communities value the trade-off between risk and compensatory payments. Again, the estimation of this parameter will require careful examination of communities likely to be affected and will yield estimates of the magnitude of a transfer payment program necessary to compensate costs and extend incentives.

\section{FOOTNOTES}

${ }^{1}$ One frequently hears the equity argument cast in terms of distributing "social bads" to all regions of the U. S. through negotiation. For example, one region may be well suited to storing radioactive waste and may be asked to do so for other regions. It would then become the responsibility of the benefiting regions to accept some equally unattractive activities, such as chemical waste repositories. In this way, no single region would become responsible for more than its just share of noxious enterprise. This arrangement can generate regional equity on a broad basis, but does not solve the problem that it will ultimately be individual communities which must deal with these facilities on a day-to-day basis. The payment plans discussed in this paper are well suited to this latter task.

${ }^{2}$ The Federal Government acts as a public marketeer when it produces goods which could have been produced in the private sector. If it does not bear responsibility for all costs of its activity, it will have an advantage over other private activities which leads to distortions in the quantities of goods produced. Recently, arguing on equity grounds, the Advisory Commission on Intergovernmental Relations has suggested that the same liability should attend all public goods production (Ebel and Towles, 1980).

${ }^{3}$ Costs due to risk accrue to host communities as well as to neighboring communities and to this extent characterizing them as external is a bit misleading. It may be argued that if a community chooses to host a waste isolation facility, it internalizes costs due to risks and is compensated for these costs, as well as opportunity costs, through the in-lieu-of tax payment.

${ }^{4}$ For simplicity, a single tax base, income, is used in this model although it is recognized that such other tax bases as real property or sales might also have been used. The conclusions drawn regarding the local tax on income are relevant to these other bases as well.

${ }^{5}$ This result is derived in most microeconomic textbooks (c.f., Ferguson, p. 40, 1969). A degree of ambiguity surrounds the interpretation of income growth as depicted in Figure 1, since the collective choice preference function may not exist uniquely (Waldauer, 1973, p. 213; Burkhead and Miner, 1971, pp. 145-171). Recently, the income constraint has been viewed as the income of the median voter and when estimating the parameters of this function, to interpret them as characterizing the demand curve of the median voter (Bergstrom and Goodman, 1973, p. 281; Ladd, 1975, pp. 145-158). When this is true, the Y-intercept changes only when the income of the median voter changes, i.e., when the community's median family income changes, whereas the $\mathrm{X}$-intercept changes according to changes in the tax status of new or current local activity.

${ }^{6} I t$ is assumed that the "income" from tourists or other nonlocal activities is indistinguishable from that arising due to local activity. Were this not the case, the community could adopt a set of optimal tax rates to discriminate among revenue sources. In effect, we assume a common tax rate is levied on all activity.

'This tax occurs because localities rely on real property rather than "income" as the tax base. Since waste facilities tend to be capital intensive, a disproportionate shift occurs.

${ }^{8}$ To simplify the analysis, we transform the choice space into per capita disposable income and per capita quantities of public goods. Per capita income is calculated by dividing local income by local population and is used here for ease of exposition. Because local public goods are divisible and consumed in fixed proportions, no loss of generality is introduced by this transformation.

${ }^{8}$ These conclusions rest upon the assumption of constant preferences. To solve the difficulty of changing preferences, we can assume alternatively that the entrance of new households is distributed such as to leave the typical voter unchanged or that we conduct the analysis holding preferences constant so as to infer whether or not the siting would be accepted by the community before the fact. 


\section{REFERENCES}

Balk, Aldred (1971). The Free List, 276 pp. New York: Russel Sage Foundation.

Baumol, W. J. (1972). On Taxation and the Control of Externalities. American Economic Review 62, 307-322.

Baumol, W. J. and Oates, W. E. (1975). The Theory of Environmental Policy, 272 pp. Englewood City, New Jersey: Prentice-Hall, Inc.

Bergstrom, Theodore C. and Goodman, Robert P. (1973). Private Demand for Public Goods. American Economic Review 63, 280-296.

Burkhead, Jesse and Miner, Jerry (1971).Public Expenditure, pp. 145-173. Chicago: Aldine Publishing Company.

Ebel, R. W. and Towles, J. E. (1980). An Examination of Payments-in-Lieu-of-Taxes for Federal Real Property, 447 pp. Washington, D.C.: United States Government Printing Office, Advisory Commission on Intergovernmental Relations.

Ferguson, Charles E. (1969). Microeconomic Theory, 520 pp. Homewood, Illinois: Richard D. Irwin, Inc.
Kneese, A. V. and Bower, B. T. (1968). Standards, Changes, and Equity Managing Water Quality: Economics, Technology, and Institutions, 328 pp. Baltimore, Maryland: Johns Hopkins Press.

Ladd, Helen F. (1975). Local Education Expenditures, Fiscal Capacity, and the Composition of the Property Tax Base. National Tax Joumal 28, 145-158.

Pigou, A. C. (1924). The Economics of Welfare, $783 \mathrm{pp}$. London: MacMillan Co.

Quigley, John and Schmenner, Roger W. (1975). Property Tax Exemption and Public Policy.Public Policy 23, 259-297.

Raimondo, Henry J. (1980). Compensation Policy for Tax Exempt Property in Theory and Practice. Land Economics 56, 33-42.

Waldauer, Charles (1973). Grant Structures and their Effects on Aided Government Expenditures: An Indifference Curve Analysis. Public Finance 28, 212-225.

Williams, Ellis T. (1955). National Forest Contribution to Local Governments. Land Economics 31, 204-214. 